\title{
LA PROBLEMÁTICA SOBRE LA EFICACIA DEL NEGOCIO JURÍDICO NULO: UN ENSAYO CRÍTICO EN HOMENAJE A JOSÉ LEÓN BARANDIARÁN
}

\author{
THE PROBLEMATIC ON THE EFFECTIVENESS OF THE LEGAL BUSINESS \\ NULL: A CRITICAL ESSAY IN HOMAGE TO JOSÉ LEÓN BARANDIARÁN
}

FORT NinAMANCCO Córdova*

Aceptado: 22/09/2017

\section{Resumen}

Los cultores del derecho contractual han manifestado recurrentemente que José León Barandiarán "no sólo fue la pluma más fina y prolífica del derecho civil de la época, sino que vivió apasionadamente la docencia (...) y que es irrealizable dar noticia de una obra tan difundida, analizada e influyente como la de León Barandiarán”. Un tema, donde la influencia de León Barandiarán se nos presenta como particularmente influyente, es el referido a las consecuencias de la nulidad. Y es que revisando los principales textos que tocan este asunto, así como sentencias emitidas por la máxima judicatura nacional, se advierte que los mismos no se han apartado de la doctrina que dejó sentada el profesor lambayecano. Sin embargo, desde hace unos años se viene difundiendo una nueva doctrina que plantea la necesidad de un nuevo enfoque para la nulidad y que, por ende, ésta sea analizada en función a

* Abogado, egresado de la Universidad Mayor de San Marcos. Docente universitario en la Facultad de Derecho de la Universidad San Juan Bautista. otras consideraciones, sustancialmente distintas a las líneas fundamentales que hace varias décadas trazara León Barandiarán.

\section{Palabras clave}

Contrato - Nulidad - Positivismo - Teorías - Judicatura - Jurisprudencia - Indemnización

\section{Abstract}

The contractual law workers have repeatedly stated that José León Barandiarán "was not only the finest and prolific pen of civil law of the time, but also lived passionately teaching ... and that it is impossible to give notice of such a widespread work, analyzed and influential as that of Leon Barandiarán. "One subject, where the influence of Leon Barandiarán is presented to us as particularly influential, is the one related to the consequences of nullity. And it is that reviewing the main texts that touch on this matter, as well as sentences issued by the highest national judiciary, you can see that they have not deviated from the doctrine that the teacher taught. However, a new doctrine has been spreading for some years, which rai- 
ses the need for a new approach to nullity and, as a result, it is analyzed in terms of other considerations, which are substantially different from the fundamental lines that several decades ago Leon Barandiarán.

\section{Keyword}

Contract - Nullity - Positivism - Theories - Judicature - Jurisprudence - Indemnification

\section{Introducción.}

Una autorizada voz sostiene que, en el Perú, el introductor de la teoría del negocio jurídico fue Manuel Augusto Olaechea y Olaechea (1880-1946), y quien la cultivó, desarrolló y difundió fue José León Barandiarán (18891987) ${ }^{1}$. En este mismo sentido, se pronunció uno de nuestros más reputados juristas, cuando afirmó que las nociones fundamentales que tenía el foro nacional sobre el negocio jurídico, a poco de promulgarse el actual código civil, se debían a "la poderosa influencia de la magnífica y brillante obra de José León Barandiarán”2.

Los máximos cultores del derecho contractual en nuestro país, por su parte, han dicho que José León Barandiarán "no sólo fue la pluma más fina y prolífica del derecho civil de la época, sino que vivió apasionadamente la docencia (...) y que es irrealizable dar noticia de una obra tan difundida, analizada e influyente como la de León Barandiarán”3.

Ante lo dicho, resulta fácil concluir que

1 Fernando Vidal Ramírez. El acto jurídico. 5ta edición. Lima: Gaceta Jurídica, 2002, pp. 23 y 24.

2 Lizardo Taboada Córdova. Acto jurídico, negocio jurídico y contrato. Lima: Grijley, 2002, pp. 15 y 16.

3 Las frases corresponden, respectivamente, a Max Arias Schreiber Pezet y a Manuel De la Puente Y LAVALLE, que constan en la presentación del libro Tratado de Derecho Civil peruano. T. II. Lima: WG Editor, 1991, de José LEón BARANDIARÁN el pensamiento del maestro sanmarquino ha cumplido un rol protagónico en la formación de la doctrina construida en torno a los institutos regulados en el libro II de nuestro actual Código Civil. Un tema, donde la influencia de León Barandiarán se nos presenta como particularmente influyente, es el referido a las consecuencias de la nulidad. Y es que revisando los principales textos que tocan este asunto, así como sentencias emitidas por la máxima judicatura nacional, se advierte que los mismos no se han apartado de la doctrina que dejó sentada el profesor lambayecano.

Sin embargo, desde hace unos años se viene difundiendo una nueva doctrina que plantea la necesidad de un nuevo enfoque para la nulidad y que, por ende, ésta sea analizada en función a otras consideraciones, sustancialmente distintas a las líneas fundamentales que hace varias décadas trazara León Barandiarán. Hay que celebrar el surgimiento de estas nuevas ideas, máxime porque tal discrepancia sería animosamente bienvenida por el maestro. Su conocido amor por el debate producto de una discusión objetiva hace que no tenga ninguna duda de ello. León Barandiarán creía firmemente, y en esto el suscrito lo sigue por completo, en que las sanas confrontaciones de ideas sólo generan beneficios para sus participantes y para la comunidad jurídica que los rodea ${ }^{4}$. Con ese ánimo, las líneas que siguen

4 Para muestra un botón: León Barandiarán era, como muchos grandes juristas de su tiempo, portador de una visión influenciada por el positivismo kelseniano, y así fue parte del jurado calificador de una tesis de bachiller que constituía una crítica sustanciosa al positivismo, la de Carlos Fernández Sessarego. Por todos es conocida la muy buena acogida de León Barandiarán a las nuevas ideas que constituían lo que ahora conocemos como teoría tridimensional del Derecho (al respecto: David Sobrevilla Alcázar. Prólogo. En: Carlos Fernández Sessarego. El derecho como libertad. Lima: Ara, 2006, pp. 11 y ss.; y José León Barandiarán. Presentación. En: Carlos Fernández Sessarego. Derecho de las personas. Lima: Grijley, 2001, pp. 9 y ss.). 
están dedicadas a efectuar un contraste constructivo entre ambas posiciones con respecto a las consecuencias de la nulidad. Esto nos permitirá repensar los planteamientos de León Barandiarán sobre el particular y de ese modo verificar su actualidad. Con esto trato de contribuir, al menos con un granito de arena, al esclarecimiento del tema.

\section{El pensamiento de José León Barandiarán} y la tesis dominante sobre la eficacia del negocio nulo en nuestra jurisprudencia $y$ doctrina dominante.

El negocio nulo no produce efectos desde su celebración, lo cual no presupone en modo alguno un pronunciamiento judicial. En sede de nulidad, el Juez simplemente declara una realidad preexistente: la ausencia de efectos del negocio. Jurídicamente hablando, una sentencia que declara la nulidad no modifica la realidad preexistente. En relación a la eficacia del negocio nulo, es esta la idea básica de la doctrina y jurisprudencia dominante en nuestro país y fue esbozada por León Barandiarán. En efecto, el maestro indicaba que "no interesa en atinencia a tal figura de la nulidad, que el acto haya producido o no sus efectos prácticos, puesto que los efectos jurídicos están ausentes desde la celebración del negocio, por ello entendía a las causales de nulidad como causales congénitas". ${ }^{5}$

Desde hace tiempo esta es la idea que acoge nuestro Corte Suprema. Puedo citar acá la Cas. $N^{\circ}$ 1843-98-ICA del 29.10.1999, la cual expresamente afirma que la nulidad es un fenómeno originario, que debe entenderse como preexistente a su declaración judicial:

"Primero: Que, de conformidad con los Artículos doscientos diecinueve y doscientos

5 José León Barandiarán. Tratado de Derecho Civil peruano. cit. p. 349. veinte del Código Civil, los actos jurídicos nulos lo son ipso jure, esto es, que no requieren de una sentencia judicial para que así lo declaren puesto que la sanción de nulidad sobre el acto jurídico opera de pleno derecho; sin embargo, en el desenvolvimiento de las relaciones jurídicas existen muchos actos jurídicos nulos que se les da la apariencia de válidos porque las partes contratantes o una de ellas actúan como si tales así lo fueran y de ello persuaden a terceras personas; empero ello sólo es una apariencia de validez; y a fin de eliminar esta apariencia se encuentra precisamente este Poder del Estado de quien, en el ejercicio del derecho de acción, el justiciable obtiene una sentencia que reconoce dicha invalidez declarando judicialmente la nulidad del acto jurídico, es decir, no está recién condenado con la nulidad un acto jurídico sino que está declarando una situación ya existente".

Años después, en la Cas. $\mathrm{N}^{\circ}$ 1323-2004-TUMBES del 10.05.2005, la Corte Suprema sigue manejando el mismo criterio, aseverando que la nulidad opera por ministerio de la ley, no por una decisión judicial. No es ésta, sino la ley, la que le arrebata los efectos al acto nulo:

"Primero: La nulidad es la sanción por la cual la ley priva a un acto jurídico de sus efectos normales, cuando en su ejecución no se han guardado los requisitos prescritos para su validez (...)”.

En idéntico términos se pronuncia la máxima instancia judicial en la Cas. $\mathrm{N}^{\circ} 1529$ 2008-ICA del 09.09.2008, donde se afirma que la nulidad opera de "pleno derecho", no gracias a una intervención judicial:

“Cuarto.- (...) En consecuencia la sentencia recurrida ha inaplicado los artículos 1625, 220 y 219 inciso 6 del Código Civil, pues el documento de donación no ha sido otorgado 
mediante Escritura Pública, y al no haber sido realizada bajo la forma prescrita por la Ley resulta nula de pleno derecho, ello en aplicación del inciso 6 artículo 219 del Código Civil (...)”

Hay que hacer, sin embargo, algunas precisiones. Veamos:

El profesor León Barandiarán destacaba una idea de Marcel Planiol, según la cual la teoría de las nulidades se ha embrollado, entre otras cosas, "por la necesidad de acudir a las justicia en todo caso en que no exista acuerdo entre las partes"6. En atención a tal problema, afirmaba que las características clásicas del acto nulo deben ser entendidas sin aplicar un rigor categórico ${ }^{7}$. En tal sentido, señala sobre la no necesidad de pronunciamiento judicial para la nulidad:

"No se requiere pronunciamiento judicial que declare que el acto es nulo. Pero si hubiera disputa entre las partes acerca de si el acto es o no nulo, corresponderá al juez resolver sobre el particular, no pronunciando su nulidad, pero sí reconociéndola o constatándola"8.

Con respecto a la ausencia de efectos, afirma que se ha hecho notar, por ejemplo, que el matrimonio que adolece de nulidad "produce los efectos de un matrimonio putativo; que una sociedad por acciones, nula por inobservancia de la formalidades de constitución, produce sus efectos en provecho de terceros, bien que la nulidad puede ser demandada por las personas interesadas, $y$, de otra parte, puede valer como sociedad de hecho"'.

\section{Como indiqué líneas arriba, la doctrina na-}

cional actual no se aleja de las consideraciones que se acaban de exponer. Así, para Fernando Vidal Ramírez, "el acto jurídico nulo lo es de pleno derecho. Ello significa que no requiere de una sentencia que así lo declare porque se trata de un acto jurídicamente inexistente, del que existe sólo un hecho con apariencia de acto, que es lo que hace necesario recurrir al órgano jurisdiccional a fin de que desaparezca la apariencia del acto (...) Si el acto es nulo, nada se ha creado ni modificado respecto de la situación jurídica que se pretendía crear o que se pretendía modificar con la celebración del acto (...) El acto jurídico nulo, pues, no requiere de pronunciamiento del órgano jurisdiccional. Sólo si una de las partes que lo celebró no acepta su invalidez corresponderá al juez declararla, sin que la sentencia que reconozca la nulidad tenga un carácter constitutivo sino meramente declarativo" ${ }^{10}$.

El profesor Vidal agrega "el acto nulo, como lo venimos viendo, lo es de pleno derecho y no surte los efectos queridos por las partes". No obstante, inmediatamente después agrega que si el acto nulo es ejecutado en el plano de los hechos, la parte que aspira a que se declare la nulidad, se verá precisada a incoar la correspondiente acción de nulidad: "la acción no va a dar creación a una nueva situación jurídica pues, como ya hemos visto, la sentencia es meramente declarativa y sólo verifica la situación preexistente a la celebración del acto nulo, ya que éste no tuvo ni puede tener eficacia alguna y, como señala Stolfi, cada uno puede reclamar que le sea restituida la prestación cumplida, restituyendo a su vez la que ha recibido. La restitución no proviene de la sentencia que declara la nulidad, sino del título anterior al acto nulo que pueda invocar cada parte respecto de la prestación que cumplió". ${ }^{11}$

10 Fernando Vidal Ramírez. Op. cit. pp. 505 y 506.

11 Ibid. p. 510. 
En sentido análogo, Aníbal Torres Vásquez afirma que "el acto que adolece de nulidad absoluta lo es ipso iure, de pleno derecho, no requiere de sentencia judicial que lo declare. Para evitar incertidumbres o cuando una de las partes amenaza con exigir o exige el cumplimiento de prestaciones en base al acto nulo o cuando este perjudica el derecho de terceros (...) se puede solicitar que judicialmente se declare la nulidad"12.

No obstante, poco antes el autor precisa que "hay actos nulos que producen efectos. Por ejemplo el contrato nulo produce efectos cuando la prestación ejecutada no puede ser restituida, ya sea porque ha prescrito la acción de restitución o debido a la naturaleza de la prestación, como es el caso del contrato de arrendamiento nulo, en el que no es posible la devolución del uso del bien por el tiempo que antecede a la declaración de nulidad. Siguiendo a una doctrina italiana, el profesor Torres señala que no es viable dar una definición general de nulidad, sino diciendo que nulo es aquel acto que produce efectos diversos respecto del acto válido y que, en particular, obliga a restituir las prestaciones"13.

Por su parte, Freddy Escobar Rozas sostiene que la nulidad del negocio jurídico, "por lo menos teóricamente supone (...) la ineficacia total y original del negocio (...) Evidentemente, el Código Civil no necesita prescribir expresamente que el negocio nulo no produce efectos $^{14}$. Añade el profesor Escobar que la nulidad no requiere ser declarada por el juez, pues la misma opera de pleno derecho. Si el negocio es nulo (...) las partes no están obligadas a ejecutarlo; y si lo hubieran hecho, están obligadas

12 Aníbal Torres Vásquez. Acto jurídico. Lima: Idemsa, 2007, p. 784.

13 Ibid. p. 783.

14 Freddy Escobar Rozas. Causales de nulidad absoluta. En: AAvv. Código Civil Comentado. T. I. Lima: Gaceta Jurídica, 2007, p. 676. a restituir lo que hubiesen recibido la una de la otra (en aplicación de las normas que regulan el pago indebido). Eventualmente, sin embargo, a las partes o a ciertos terceros les puede interesar que el juez reconozca, mediante una sentencia meramente declaratoria, que el negocio es nulo"15.

No obstante, este autor afirma que el negocio nulo puede producir efectos "no negociales", los cuales tiene por función "tutelar ciertos intereses de una de las partes. Esto ocurre, por ejemplo, cuando trasgrediendo las reglas de la buena fe objetiva, una de las partes induce a otra a celebrar un negocio nulo; o cuando ignorando la existencia de una causal de nulidad, una de las partes ejecuta a favor de la otra una de las prestaciones previstas en el negocio". En el primer caso, la parte engañada puede exigirle a la otra el pago de una indemnización (supuesto de responsabilidad precontractual). En el segundo caso, la parte que realizó la prestación tiene el derecho de exigir la restitución. Es menester precisar que, conforme indica Escobar, los efectos se producen en virtud de las normas, empero los "efectos negociales" son aquellos que-sin dejar de ser producidos por las normas- se "nutren" de la reglamentación de intereses fijada o acordada por las partes que celebran el negocio. Los efectos "no negociales", en cambio, no se "alimentan" de la referida reglamentación. Por eso, asevera que "la nulidad determina que el negocio jurídico no produzca los efectos negociales, que son los efectos deseados por la parte o las partes que lo celebran"16.

Lizardo Taboada Córdova afirmaba que "los actos nulos nacen muertos y por ende no producen ninguno de los efectos jurídicos que tendrían que haber producido ${ }^{17}(\ldots)$ la nulidad opera de pleno derecho, siendo por tanto

15 Ibid. p. 689.

16 Ibid. p. 677.

17 Lizardo Taвoada Córdova. op. cit. p. 321. 
la sentencia que declare judicialmente la nulidad (....) meramente declarativa, al limitarse a constatar que se presentó y operó la causal de nulidad y que el negocio jurídico nació muerto sin producir ninguno de sus efectos jurídicos (...) si bien es cierto que la nulidad opera de pleno derecho, sin necesidad de sentencia alguna, es conveniente para efectos prácticos contar con una sentencia que declare judicialmente la nulidad, a fin de tutelar fundamentalmente a los terceros de la apariencia de validez de un acto nulo"18.

Otro connotado profesor que se ha ocupado del tema, Marcial Rubio Correa, tiene escrito lo siguiente:

"La consecuencia esencial de la nulidad, es que convierte al acto respectivo en ineficaz perpetuamente y desde el inicio"19. Luego, haciendo suya la posición de Vidal, indica que la resolución judicial tendrá una utilidad práctica cuando exista controversia entre las partes con respecto a la presencia o no de la causal de nulidad ${ }^{20}, \mathrm{y}$ añade además que "la sentencia de nulidad no es constitutiva sino declarativa: el acto nulo tiene un vicio que lo invalida desde su propio origen. Como se dijo antes, la nulidad es ipso iure. Inclusive, en el artículo 1643 parece haber un reconocimiento expreso de ello al hablarse de casos de "invalidación de pleno derecho"21.

Si bien existen algunas diferencias entre las opiniones transcritas, lo cierto es que tales diferencias no pueden ser catalogadas como esenciales. Por el contrario, no resulta dificultoso notar que dichas opiniones tienen una coincidencia fundamental: el negocio nulo no

18 Ibid. p. 234 y 325

19 Marcial Rubio Correa. Nulidad y anulabilidad. La invalidez del acto jurídico. Lima: Pontificia Universidad Católica del Perú, 2001, p. 27.

20 Ibid. p. 30.

21 Ibid. p. 59. produce, desde su celebración, los efectos que como negocio debería producir. Si hay una discrepancia entre las partes al respecto, será necesaria la intervención del juez o árbitro, quien deberá verificar la presencia de la causal de nulidad. Si declara la nulidad, ello significará que el negocio nunca produjo los efectos que le corresponderían justamente por la presencia de la causal. Si el juez o árbitro no declara la nulidad, pues debe considerarse que el negocio siempre produjo tales efectos, toda vez que la causal nunca estuvo presente. Todo ello sin perjuicio de que el negocio nulo puede producir los llamados efectos no negociales, que son establecidos directa y únicamente por la ley, no dependiendo en absoluto de la voluntad de las partes plasmada en el negocio, tal como en su momento lo advirtió León Barandiarán, y lo resaltan los profesores Torres y Escobar.

\section{Una doctrina francesa invade el Perú: el negocio nulo no lo es de pleno derecho.}

Como adelanté al inicio del presente trabajo, en nuestra doctrina se ha desarrollado una tesis que contradice la base de la doctrina dominante, ya que sostiene con firmeza que el negocio nulo produce efectos normalmente desde su celebración, y que los mismos sólo pueden ser suprimidos por la declaración de nulidad del juez o árbitro. Tan interesante postura es defendida principalmente por los profesores Juan Lohmann Luca de Tena y Juan Espinoza Espinoza, aunque le antecede una doctrina desarrollada en Francia en las primeras décadas del siglo XX. Veamos:

"Actualmente la nulidad absoluta ya no opera de pleno derecho, aun cuando se trate de un acto que lesione abiertamente el orden público. Al respecto, recordemos que desde el siglo XVI Coquille e Imbert nos hablaban de la acción de declaración de nulidad. Esta tesis ha recibido, posteriormente, su confirmación por 
dos reglas de origen consuetudinario, cuya influencia es notoria. Existe desde luego, la regla de que en Francia están prohibidas las vías de hecho y que hay también el principio aún más explícito de que nadie puede hacerse justicia por sí mismo. Si se agrega, finalmente, la fórmula no menos respetada de que el documento es válido hasta en tanto se declare su nulidad (provision est due au titre), se comprenderá fácilmente que aún cuando nulo, el acto que tiene apariencia de regularidad no puede ser rechazado de plano $^{22}$.

\section{(...)}

Y desde luego ¿qué caminos puede seguir el acto nulo?

Es incuestionable que a pesar de la oposición del orden público, las partes pueden destruirlo amigablemente o ejecutarlo, y la ejecución producirá todos sus efectos jurídicos en tanto que un tercero interesado o las partes mismas no lo hayan atacado. Pero si las partes no están de acuerdo para rehacer o destruir su relación jurídica ilícita, será indispensable recurrir a la justicia, lo que se hará por una demanda de nulidad de carácter preventivo. En este caso, pues, la acción de nulidad tendrá por fin privar al acto ilícito de toda su fuerza obligatoria, poner el sello de la condenación sobre todas las reglas jurídicas en él contenidas"23.

En la primera edición de su muy importante libro dedicado al negocio jurídico, Lohmann indicaba que si celebra un negocio nulo, "los interesados, atendiendo al estado de invalidez del negocio pueden hacer como si éste nunca se hubiera celebrado (...). Hasta aquí la acción de nulidad no tiene importancia ni trascendencia entre las partes. Pero cuando alguna

22 Ibid. p. 59.

23 Georges Lutzesco. Teoría y práctica de nulidades. Traducción de Manuel Romero Sánchez y Julio López de la Cerda. Médico D. F.: Porrúa, 1993, p. 270.

de ellas estima que es el único camino para resolver discrepancias sobre si el negocio en que intervino está afecto a la sanción y quiere que se constate su carencia de valor obligatorio o vinculante, entabla entonces la acción de nulidad absoluta a fin de que se certifique y declare judicialmente la nulidad del negocio, porque el acto, aunque inválido ab origine y de pleno derecho, requiere de sanción judicial y nadie puede hacerse justicia por sí mismo (...)”. Según Lohmann, esto explica que "el negocio nulo produce efectos como válido hasta la sentencia judicial que lo sancione"24.

Años después, el autor nos ilustraría más con respecto a sus ideas, separándose aún más de la doctrina dominante:

"La nulidad es el estado jurídico del acto después de constatada y declarada judicial o arbitralmente su invalidez, porque las partes no pueden declarar por sí mismas el vicio y determinar la sanción jurídica. Hasta antes de la declaración habrá causal de nulidad, pero no estado jurídico de tal, que sólo hay, jurídicamente, desde que se declara con efecto retroactivo. Aunque el negocio jurídico esté intrínsecamente afecto a una causal de nulidad, las partes solamente quedarán liberadas de cumplir lo que en él se hubiese estipulado cuando se declare su nulidad, aunque con efectos retroactivos, como he dicho. (...) La declaración de nulidad tiene por objeto la supresión de los efectos jurídicos, y en cuento sea posible los prácticos, mediante restitución de prestaciones, que haya producido o pueda producir el acto inválido (...) Conviene dejar afincado lo anterior para recalcar que los estados de invalidez y nulidad absoluta están sustraídos a la facultad dispositiva de las partes del acto afectado"25.

24

25 dad manifiesta. Su declaración judicial de oficio. En: Ius et veritas. $\mathrm{N}^{\circ} 24$. Lima, 2002, pp. 57 y 58. 
En sentido semejante, Espinoza afirma:

"Tradicionalmente, al referirse a la nulidad, se ha esgrimido el aforismo romano quod nullum est, nullum producit efectum. Sin embargo, este criterio no se aplica siempre. Con razón se ha afirmado (cita a León Barandiarán) que esta regla no tiene una aplicación inflexible ${ }^{26}$. El autor nos esclarece su posición de esta manera:

Ante la celebración de un acto nulo, caben tres posibilidades: i) que las partes no se exijan entre sí el cumplimiento del acto (hecho que no produce efectos jurídicos), ii) que una de las partes haya cumplido con realizar lo acordado en el acto afectado de nulidad y la otra no (frente a lo cual, la parte afectada puede, o no, reclamar lo que le corresponde), y iii) que ambas partes hayan cumplido con ejecutar el acto afectado de nulidad.

El hecho de que el acto jurídico afectado de nulidad no produzca efectos jurídicos depende, inicialmente, de las partes. Si es que existe discusión respecto de la producción (o no) de dichos efectos, interviene el juez, declarando dicha nulidad. La resolución judicial de la nulidad tienes efectos ex tunc (o sea, retroactivos a la fecha de celebración del acto) (...) En opinión que comparto, el adagio quod nullum est, nullum producit effectum, notoriamente, reflejaba una idea de nulidad que se identificada con la inexistencia. Por ello, el acto jurídico afectado de nulidad produce efectos jurídicos precarios y dejará de hacerlo cuando haya una sentencia que lo declare como tal"27.

Pese a su gran coincidencia en torno a la eficacia del negocio nulo, existe una diferencia no poco relevante en las apreciaciones de estos dos connotados profesores. En efecto, la tesis

26 Juan Espinoza Espinoza. El acto jurídico negocial. Lima: Rodhas, 2012, p. 480.

27 Ibid.pp. 480 y 481. de Espinoza hace depender de la voluntad de las partes la eficacia del negocio nulo, cosa que también pareciera hacer Lohmann en su libro, pero que expresamente rechaza después en su artículo, al resaltar que las partes nada pueden hacer en relación a los estados de invalidez y nulidad del negocio que celebren.

4. Actualidad del pensamiento de José León Barandiarán: un constructivo contraste de opiniones.

La divergencia entre las dos tesis sobre la eficacia del negocio nulo se centra en: i) la relación que tal eficacia guarda con dos factores: i) la voluntad de las partes, y ii) la prohibición general de autotutela. Es preciso, entonces, detenernos en el análisis comparativo de ambas posiciones en relación a los factores mentados.

\subsection{La eficacia del negocio nulo y las ac- tuaciones de las partes.}

Como ya anoté líneas arriba, Espinoza considera que la eficacia del negocio nulo depende de la voluntad de las partes. Pienso que Lohmann tuvo la misma postura en su libro, cuando afirmaba que si el negocio nulo no era ejecutado por las partes, la acción de nulidad era intrascendente. Esta acción cobraba relevancia si es que el negocio afectado de nulidad llegaba a ejecutarse en el plano de los hechos. Por consiguiente, si sólo con la sentencia o laudo arbitral el negocio puede ser nulo, debe entenderse que cuando las partes no ejecutan las reglas contenidas en el negocio nulo, éste lo es sin que sea preciso que así lo declare una sentencia o laudo. Ello significa que si las partes ejecutan el acto que contiene una causal de nulidad, el mismo produce efectos y sólo perderá esta eficacia cuando así lo declare el juez. Si las partes no lo ejecutan, pues ya no hay eficacia y, por ende, ninguna sentencia o laudo se requiere para que así sea. Ergo, la eficacia del 
acto nulo depende de la voluntad de las partes que lo celebran.

No parece que esta idea pueda ser compartida.

En efecto, la eficacia jurídica de un hecho (como lo es el negocio, aunque sea nulo) pertenece a un plano que podemos denominar "realidad jurídica”, cuya dinámica se encuentra dominada por el contenido de las normas, no por lo que ocurra o deje de ocurrir en el plano de la realidad empírica. Esta premisa ya había sido destacada por Rudolf Stammler, pero, como lo resalta una autorizada doctrina italiana, fue sentada en la teoría general del Derecho por Hans Kelsen ${ }^{28}$.

El jurista alemán sostenía que si entendemos por vigencia la posibilidad de hacer efectiva, en la realidad de los hechos, una determinada aspiración, pues tal posibilidad no forma parte de la esencia de las reglas de Derecho. Tales reglas contienen conceptos y, entendía Stammler, el hecho de que un concepto imponga su existencia en la realidad, no añade nada a su contenido. En tal sentido, decía:

28 Renato Scognamiglio. Fatto giuridico e fattispecie complessa (considerazioni critiche in torno alla dinámica del Diritto). En: Rivista Trimestrale di Diritto e Procedura Civile. Anno VIII. Milán: Giuffrè, 1954, p. 337. Cuando se estudia el hecho jurídico, dice el autor citado, se advierte que su teoría se desarrolla en una doble dirección: en sede de teoría general, o incluso de filosofía del Derecho, se trata de buscar la específica naturaleza del supuesto de hecho; en sede de los diversos campos del Derecho, se trata de aplicar el esquema de tal naturaleza para lograr una mejor sistemática y conocimiento de los fenómenos dinámicos que se encuentran en cada uno de dichos campos (Loc. cit.). En consecuencia, en modo alguno debe extrañar al lector que me vea en la necesidad de acudir a fuentes de carácter teórico general, puesto que en este trabajo se está tratando de aplicar una noción adecuada de hecho jurídico para tratar de obtener un mejor entendimiento de un fenómeno dinámico perteneciente al campo del Derecho civil patrimonial: la eficacia del negocio jurídico
"Para fijar el concepto de Derecho, en cuanto concepto formal, no es preciso acudir a la noción de su efectividad (...) El concepto de crédito, por ejemplo, no requiere que se exija el pago, y hasta es indiferente en cuanto al concepto el que el crédito no pueda hacerse efectivo por insolvencia del deudor. Si queremos poner de manifiesto la distinción fundamental entre derechos reales y derechos de obligación, exponiendo cuáles sean las notas diferenciales del concepto de cada uno de estos grupos de derechos, tenemos que hacer abstracción de cuanto se refiera a su efectividad. Y lo mismo ocurre con el concepto formal del Derecho por oposición al de la moral o al de los usos sociales. La distinción que separa estos conceptos debe dilucidarse científicamente atendiendo a las notas permanente que lo caracterizan (...). Lo relativo a la vigencia afecta a todas las reglas por igual, como se ha dicho, sin formar parte característica de ningún concepto"22.

Recuérdese que las normas no quedan sin efecto jurídico por el hecho de ser sistemáticamente desobedecidas en la realidad de los hechos. La efectividad en el plano fáctico (o vigencia, en palabras de Stammler), no influye sobre la juridicidad de las normas. La consagración de esta idea en la teoría general del Derecho, marcó la superación del postulado básico de la escuela histórica del Derecho, según el cual el Derecho consuetudinario debía ser capaz de imponerse al Derecho legislado. Actualmente (tal como ya ocurría en los días del célebre profesor Berlinés), no se puede poner en duda que una práctica reiterada entre los ciudadanos, o costumbre, es incapaz de privar de eficacia jurídica a una ley debidamente promulgada ${ }^{30}$. Será, qué duda

29 Rudolf Stammler. La génesis del Derecho (compilación de conferencias). Traducción de Wenceslao Roces. Lima: Ara, 2005, pp. 51 y 52.

30 Ibid. p. 24 (sin embargo, no puedo dejar de mencionar que Stammler manejó una perspectiva muy particular sobre la relación entre el supuesto de hecho y 
cabe, una norma socialmente ineficaz, pero jurídicamente no lo es.

Quizá bajo la influencia de la escuela histórica, que tanto peso otorgaba en la configuración del Derecho a lo que efectivamente acontecía en la realidad social, explica que un sector de la doctrina alemana de mediados del siglo XIX entendiera que el hecho mismo (entendido como fenómeno natural), y no otra cosa, era el productor de los efectos jurídicos que le correspondían ${ }^{31}$. No tardó la doctrina en superar este punto de vista al advertir que resultaba inapropiado entender que la realidad jurídica pertenecía, sin más, a la experiencia sensible o realidad empírica. Es a partir de allí que, según indica un autorizado cultor de la teoría general del Derecho, a lo largo del siglo $\mathrm{XX}$ se fueron plasmando las tres principales teorías en torno al efecto jurídico.

Philipp Lotmar, y poco después Ernst Zitelmann, distinguidos civilistas alemanes de fines del siglo XIX e inicios del siglo pasado, fueron los primeros en denunciar que un evento que podemos apreciar con nuestros sentidos, en ningún caso es capaz de producir, por sí mismo, efectos jurídicos. Al igual que las leyes de la física, decían estos autores, las normas jurídicas tienen también la estructura de proposiciones hipotéticas o condicionales y, por ende, enlazan a un evento condicionante (la causa), un evento condicionado (el efecto). Pero la relación de causalidad en las normas no es igual, sino tan sólo análoga, a la que existe en las leyes físicas. Por tanto, no hay identidad entre ambas clases de preceptos ${ }^{32}$.

los efectos. Empero, como es fácil notar, esto no altera en nada la pertinencia de la idea que he tomado de este ilustre autor: lo que en plano de los hechos ocurra, no altera el carácter o perfil jurídico de las normas o conceptos).

31 Renato Scognamiglio. Op. cit. p. 335.

32 Ángelo FalzeA. Efficacia giuridica. En: ID. Voci di teoría generale del diritto. Milán: Giuffrè, 1985, p. 246.
Siegmund Schlossmann condenó esta forma de ver las cosas y propuso una segunda teoría: el Derecho no pertenece al mundo de la materia, sino al mundo del espíritu, en consecuencia no es posible establecer analogía alguna entre las normas jurídicas y las leyes físicas. En la norma jurídica no es factible apreciar un nexo causal, sino un nexo psicológico de motivación, en el sentido de que el evento fáctico viene a constituir, en un plano psicológico o mental, el motivo del vínculo jurídico establecido por el legislador. Este enfoque del efecto jurídico tendría una enorme influencia en la doctrina europea hasta bien entrado el siglo $\mathrm{XX}^{33}$.

La tercera teoría rechaza la explicación causal y la psicológica de la relación entre el hecho y el efecto jurídico, afirmando que si bien es imposible reducir el efecto jurídico a un efecto físico, tampoco es posible atribuir al efecto jurídico una existencia sólo psíquica y, por tanto, meramente subjetiva. Los autores de defensores de esta teoría ${ }^{34}$ parten de la consideración de que es necesario garantizar el carácter inmaterial del efecto jurídico, sin que ello implique negar su objetividad. Según esta corriente de opinión, tal objetivo se alcanza mediante un enfoque lógico de la norma jurídica. La causalidad jurídica, así, no es más que pura condicionalidad lógica, misma que sirve para definir, en el puro plano lógico, lo que constituye la razón o el fundamento (grund) de una determinada consecuencia (folge). Cabe destacar que la tesis lógica no deja de subrayar el carácter ideal del efecto, pero sería Hans Kelsen quien haría de tal carácter un elemento fundamental para la comprensión de la realidad ju-

33 Siguieron a Schlossmann, entre otros, Ernst Bierling, Theodor Kipp, Wilhem Fuch y, en Italia, Domenico Rubino (así lo informa Ángelo Falzea. Op. cit. p. 247).

34 Fritz Klingmüller, Julius Binder, Fritz Von Hippel, Karl Peter y, el más célebre sin duda, Karl Larenz (así lo informa Angelo FalzeA. Op. cit. p. 248). 
rídica. Como se sabe, el famoso jurista austriaco niega la existencia real del efecto, partiendo de la concepción de la norma como deber-ser, y contraponiendo el deber ser (sollen) al ser (sein) y a la realidad del mundo empírico ${ }^{35}$.

En tal contexto, se tiene que de los dos términos que conforman la relación de causalidad jurídica, el primer término, el hecho jurídico, no tiene nada de particular frente a los otros hechos observables en el mundo real y material; en cambio, el segundo término, el efecto jurídico, es algo peculiar del mundo del Derecho, algo que tiene una neta existencia jurídica y no es determinable materialmente, como lo puede ser el efecto de una causa física cualquiera. Si bien esta es sólo una idea básica sobre la cual los cultores de la teoría general han discutido en la búsqueda de alcanzar un claro y determinado concepto de eficacia, tiene que aceptarse (y esto es lo que me interesa dejar sentado en este trabajo) que ya no puede ser seguida aquella postura doctrinal que establecía un vínculo íntimo entre el efecto jurídico y el efecto material, de manera que, por ejemplo, se consideraba como efecto jurídico, en lugar de la obligación, el cumplimiento o la ejecución forzada; en vez de la sujeción a la pena, la ejecución de la pena; en vez del derecho al goce, la fruición del bien ${ }^{36}$.

Así las cosas, la eficacia del negocio nulo no puede depender de aquello que las partes decidan hacer o no hacer, de tal manera que si se ejecuta el negocio nulo, éste desplegaría sus efectos como si fuera un negocio válido y eficaz, hasta que un juez o árbitro lo declare nulo. Por el contrario, depende de lo que el ordenamiento jurídico disponga al respecto. Si la causal de nulidad está presente desde la celebración negocio, esta circunstancia no puede dejar de tener un efecto en la realidad jurídica.
La presencia de la causal no puede ser negada o considerada jurídicamente irrelevante por el hecho de que no exista declaración judicial o arbitral de nulidad. Si se dice que mientras no exista decisión judicial o arbitral, sólo hay causal, pero no ineficacia, pues se está haciendo depender la eficacia jurídica de un hecho determinado (la presencia de la causal de nulidad), exclusivamente de la -eventual- verificación de otro evento (que las partes decidan iniciar un proceso). Creo que con este discurso se entrecruzan de forma indebida la realidad jurídica y la realidad material. Me recuerda al ejemplo de Ángelo Falzea citado líneas arriba: el negocio que adolece de causa de nulidad es como el reo ya sentenciado, si éste consigue escapar, pues no puede considerársele como sujeto condenado, porque la pena no es el efecto jurídico, si no la ejecución de la misma por parte de las autoridades respectivas. De igual forma, podría decirse que si el negocio nulo "escapa" del proceso declarativo de nulidad, pues sigue produciendo sus efectos normalmente, como si fuera válido. Aunque sea efectivamente contrario al ordenamiento, el negocio produce sus efectos jurídicos hasta que un juez o árbitro dictamine lo contrario. Siendo ello así, la reacción del sistema jurídico frente a un negocio que contradice sus directrices, no depende del sistema en sí, sino de un eventual acontecimiento de la vida material: la expedición de una sentencia o laudo arbitral.

Sin embargo, por las razones expuestas líneas arriba, tengo la convicción de que la reacción del ordenamiento frente al negocio nulo (que no es otra cosa que la eficacia jurídica del tal negocio) es algo que compete a la realidad jurídica, no a la realidad material, por lo que tal reacción no puede depender de lo que pase o deje de pasar en el mundo de la experiencia sensible ${ }^{37}$. Asunto distinto, por supuesto, será 
que esa reacción o eficacia jurídica tenga un cotejo en la realidad social. Se trata de dos realidades distintas, lo ideal es que ambas coincidan pero, como sabemos, no necesariamente es así. La consecuencia jurídica, que se desata en el mundo de la realidad jurídica, puede o no tener repercusiones en el plano de los hechos ${ }^{38}$.

Por ello, me opinión se adhiere a las premisas sentadas por León Barandiarán y que configuran a nuestra doctrina dominante. Ésta resulta más acorde con la idea que entiende que la eficacia jurídica se desenvuelve al margen del mundo empírico.

En ese entendido, si lo establecido por las partes en el negocio resulta conforme para el ordenamiento, pues se tendrá un tratamiento positivo del negocio. Si tal conformidad no existe, pues se tendrá un tratamiento negativo. El tratamiento, sea positivo o negativo, se determina al momento de celebrarse el negocio, no luego de que las partes decidan ejecutar o no lo previsto en él. Y el tratamiento negativo más grave es, como se sabe, la nulidad ${ }^{39}$. Así también se pronuncia un reputado autor, cuando sostiene que la anulabilidad implica un negocio que deviene ineficaz por decisión judicial, mientras que la nulidad se traduce en una falta de efectos del negocio por imperio de la ley (de pleno derecho), y esto en modo alguno se contradice con el hecho de que, en

por la ley y no por una sentencia judicial: Francesco Messineo. Il contratto in genere. T. II. Milano: Giuffrè, 1972, p. 170.

38 Es importante advertir que así también lo entiende la doctrina nacional que ha brindado una atención más detallada a la noción de efecto jurídico. Así, indica que un evento puede perfectamente desplegar sus consecuencias jurídicas, sin que éstas tengan alguna materialización en la vida real, toda vez que tal materialización es meramente contingente: Marcial Rubio Correa. El sistema jurídico. Introducción al Derecho. Lima: Pontificia Universidad Católica del Perú, 2010, pp. 88 y ss.

39 Franco Carresi. Il contratto. T. II. Milán: Giuffrè, 1988, pp. 565-568. caso de controversia, se tenga que recurrir al juez para que declare la nulidad. Si se trata de un negocio anulable, es la decisión del Juez la que priva al negocio de sus efectos. Si se trata del negocio nulo, el juez simplemente se limita a constatar la realidad jurídica (no fáctica) preexistente, o sea la falta de efectos jurídicos (negociales) ${ }^{40}$.

¿Y el plazo de prescripción de la acción de nulidad? ¿Si el plazo vence, eso implica que el negocio se vuelve válido si es que el demandado excepciona? Debo reconocer que este punto en particular no es simple, pero considero que no resulta primordial para defender la tesis mayoritaria de la originaria ineficacia del negocio nulo. Así es, la prescripción es un aspecto que tiene un importante rasgo procesal, cosa que no ocurre con la eficacia del negocio nulo. Si alguien está interesado en conseguir la declaración de nulidad con miras a deshacer lo ejecutado en virtud de un negocio nulo, pero ha dejado transcurrir el plazo de prescripción y el demandado ha planteado la excepción correspondiente, pues sencillamente no podrá obtener la tutela procesal que le correspondería según el derecho sustantivo. Esto no significa que el negocio nulo produzca efectos jurídicos (negociales), puesto que, como ya se dijo, la eficacia jurídica puede no corresponder con lo que ocurre en el plano fáctico.

Para advertir que una vicisitud procesal no se vincula con la eficacia de un negocio nulo, piénsese, por ejemplo, en un negocio sin defecto alguno, pero celebrado utilizando la sola forma verbal. El negocio puede no alcanzar tutela procesal de ninguna clase por falta de la prueba respectiva, pero esto no significa que no haya generado efectos jurídicos. Sí ha producido sus efectos según el derecho sustantivo, pero la falta de pruebas le arrebata la tutela que

40 Massimo Bianca. El contrato. Traducción de Fernando Hinestrosa y Égdar Cortés. Bogotá: Universidad Externado de Colombia, 2007, pp. 649 y 662. 
brinda el proceso (o un arbitraje). En este caso, sin duda que los derechos (sustantivos) han surgido (hay eficacia jurídica), pero, lastimosamente, no se podrán hacer valer mediante un proceso ${ }^{41}$. Tal como ocurre con la prescripción, este asunto de la prueba no nos puede llevar a conclusiones sobre la eficacia de un negocio en el terreno sustantivo. Por tal razón, no me encuentro de acuerdo con la doctrina que se basa en la regulación de la prescripción para analizar la eficacia del negocio nulo ${ }^{42}$.

Consiguientemente, en sede de nulidad, la intervención del juez no es una necesidad jurídica para la determinación de la ineficacia (como sí lo es para la anulabilidad), sino tan solo una necesidad práctica, tal como lo advirtiera León Barandiarán: haya o no proceso, el negocio nulo no produce efectos (negociales). Que se presente o no una controversia, constituye un eventual problema de orden práctico. Acá es oportuno mencionar las afirmaciones de una acreditada doctrina española:

"La nulidad determina una absoluta inatendibilidad del contrato y por consiguiente no es necesario que ninguna acción sea ejercitada. Sin embargo, por razones de orden práctico, puede pretenderse un pronunciamiento de los tribunales en orden a la nulidad, a fin de que la cuestión quede definitivamente zanjada. La acción de nulidad es meramente declarativa. Igualmente lo es la sentencia que como consecuencia del ejercicio de tal acción recaiga. No crea el estado de ineficacia del contrato, sino que se limita a constatarlo" 43 .

41 Hernando Devis Echandía. Teoría General de la Prueba Judicial. T. I. Bogotá: Temis, 2002, pp. 4 y 5.

42 Juan Espinoza Espinoza. Op. cit. p. 481.

43 Luis Diez Picazo. Fundamentos de Derecho Civil Patrimonial. Madrid: Civitas, 2007, p. 473.

\subsection{Eficacia del negocio nulo y prohibi- ción general de autotutela.}

Si se entiende que el negocio nulo no vincula a las partes desde el momento de su celebración, pues tal cosa no cambiará por el hecho de que las partes decidan ejecutarlo. Aquí cabe resaltar, como ha sido inteligentemente notado, que no puede considerarse como un efecto del negocio nulo la obligación de restituir lo que una parte haya recibido de la otra al ejecutarse el negocio nulo, porque es claro que tal obligación deriva-en rigor- del hecho de la ejecución, que precisamente por carecer de causa constituye un pago indebido $y$, por ende, puede ser materia de repetición. El negocio nulo no es más que el mero motivo de la realización del pago (indebido) ${ }^{44}$.

Si celebro con usted, amable lector o lectora, un negocio nulo, pues según la tesis mayoritaria no me encuentro obligado a ejecutar las prestaciones pactadas que se encuentran a mi cargo. Si usted insiste en que cumpla, yo puedo mantenerme en mis trece y negarme. Mi omisión no constituye ilícito. Naturalmente, por el principio general de prohibición de autotutela, usted no puede por sí mismo coaccionarme para cumpla con el negocio. De la misma manera, en virtud de ese mismo principio, yo tampoco puedo usar la fuerza contra usted para que deje de insistir en el cumplimiento del negocio. Si usted está convencido de que el negocio no es nulo, pues demandará su cumplimiento, ante lo cual yo tendría que demostrar a la autoridad jurisdiccional la presencia de una causal de nulidad. Si yo me encuentro convencido de la nulidad, pues solicitaré que el juez haga la constatación respectiva: que el negocio nunca produjo efectos vinculantes. Dado que el negocio es nulo, el juez tendría que rechazar su demanda y amparar la mía, de modo que mi omisión no constituye ilícito.

Franco CARresi. Op. cit. p. 567. 
Si por el contrario, el juez considerara que el negocio es válido, pues ésta sería la constatación oficial de la realidad jurídica, con la cual podemos o no estar de acuerdo, y tendría que hacerme responsable por los daños generados por mi omisión inicial ${ }^{45}$.

Repárese en la necesidad de una constatación "con valor oficial" de la presencia de la causal de nulidad en el negocio. No tiene utilidad la constatación de un investigador, de un profesor o la de un prestigioso estudio de abogados. Lo que, en verdad, "sirve" es la constatación o verificación oficial, o sea la del juez. Por eso, los procesos que buscan la declaración de nulidad tienen un fundamento práctico, no jurídico.

En consecuencia, la prohibición general de autotutela no es un indicativo de que el negocio nulo requiera necesariamente un pronunciamiento judicial. $Y$ es que cuando me niego a ejecutar el negocio porque me encuentro convencido de que el mismo es nulo, no estoy empleando autotutela. Ésta se da cuando un conflicto es solucionado a través del uso de la fuerza por una de las partes implicadas ${ }^{46}$ : ciertamente el no cumplir lo previsto en un negocio no significa emplear la violencia contra la otra parte a fin de solucionar un conflicto.

El respeto a la prohibición de autotutela no implica que el negocio nulo tenga que respetarse necesariamente hasta que un juez

45 Supóngase que una persona con especial "habilidad" comete un delito, pero logra que inculpen a un inocente del mismo y la condenen. En el plano sustancial, qué duda cabe, la persona condenada no ha cometido delito, pero, otra vez, una cuestión procesal hace que su inocencia no tenga una relevancia en el plano de los hechos. Como ya se dijo, la consecuencia jurídica puede o no materializarse en el plano de los hechos.

46 Lorenzo Zolezzi IbÁrCena. Autotutela, autocomposición y heterocomposición. En: Ágora. No 9-10. Lima: Universidad Inca Garcilaso de la Vega, 2010, p. 461. o árbitro dictamine su nulidad. Si el negocio no se cumple sin más, no hay autotutela. Ésta surge no ante la sola negativa de cumplir con lo previsto en el negocio, sino cuando una parte, usando la fuerza, pretende hacer que la otra cumpla con el negocio o, por el contrario, que deje de insistir en su cumplimiento. Además, nótese que también podría sostenerse lo contrario: negocios nulos o válidos sólo producen efecto desde que un juez o árbitro así lo dispone, toda vez que si una parte se niega a cumplir con el negocio, pues a la otra no lo quedará más remedio que acudir a la autoridad jurisdiccional para obtener el cumplimiento.

La prohibición de emplear la autotutela es un asunto procesal, que no influye en la eficacia del negocio nulo.

Ha sido la doctrina francesa, como ya vimos, la que ha invocado la prohibición de autotutela para sostener que siempre se requiere el pronunciamiento judicial en sede de nulidad. No obstante, como bien sugiere un eximio autor ${ }^{47}$, esta es una precisión que se hace a propósito de la restitución, no con un carácter general, de tal modo que si se ha ejecutado el negocio nulo, ninguna de las partes, por sí misma, puede usar la fuerza y lograr la restitución. Si una parte busca conseguir que se le restituya lo que ha entregado a la otra parte, necesariamente tendrá que recurrir al juez. No obstante, como ya se dijo más arriba, es esta una cuestión de orden práctico, no jurídico. Además, como se dijo también, la obligación de restitución no es un efecto del negocio nulo, sino del hecho mismo de la ejecución de lo previsto en dicho negocio.

La doctrina francesa clásica que ha tocado el tema, así lo entiende. Si la nulidad del negocio es manifiesta, o a toda luz evidente, pues

47 Rodolfo Sacco. En: Rodolfo Sacco y Giorgio DE Nova. Il Contratto. T. II. Turín: Unione Tipografico-Editrice Torinese, 1993, p. 484. 
en la práctica difícilmente una de las partes se atreverá a judicializar el asunto, de modo que no será necesario (en la praxis) un pronunciamiento judicial o arbitral que constate la nulidad. Pero si la nulidad no resulta manifiesta, muy probablemente una de las partes pondrá en discusión la nulidad y será inevitable acudir a la autoridad jurisdiccional, para que no quede ninguna duda al respecto ${ }^{48}$. Por eso, cuando la doctrina francesa critica al Código Civil alemán por consagrar la nulidad de pleno Derecho, lo hace para llamar la atención sobre el hecho de que esto no puede de ninguna manera significar que, en el plano de la práctica, no se requiere intervención del Juez, no para indicar que el negocio nulo produce plenamente sus efectos como válido mientras la autoridad jurisdiccional no diga otra cosa. Insisto, la intervención del juez en sede de nulidad se justifica en una necesidad de orden práctico, no jurídico:

"Las legislaciones modernas han intentado evitar el acudir a los tribunales, permitiendo a la parte que invoca la nulidad dirigir al otro contratante una "declaración de nulidad". La experiencia ha demostrado que ese sistema no aporta ninguna simplificación real; porque el otro contratante no deja casi nunca de sostener que el contrato es válido; debe acudir entonces al tribunal para que se verifique esa validez" ${ }^{49}$. Nótese, pues, el carácter netamente práctico de esta observación.

Creo que la tesis que sostiene la eficacia normal del negocio nulo, nos ayuda a mejorar nuestra percepción de las directrices que

Así: Marcel Planiol y George Ripert. Tratado Práctico de Derecho Civil francés. T. VI. Parte I. Traducción de Mario Díaz Cruz. La Habana: Cultural, 1946, pp. 418 y 419; Henry, Leon y Jean Mazeaud.Lecciones de Derecho Civil. Parte II. Vol. I. Traducción de Luis Alcalá-Zamora y Castillo. Buenos Aires: Ediciones Jurídicas Europa-América, 1960, p. 337.

Henry, Leon y Jean Mazeaud. Ult. cit. dejó plasmadas León Barandiarán en su obra. Recuérdese que él decía, con certeza en nuestro concepto, que el negocio nulo no producía sus efectos (normales), desde un inicio y, sin perjuicio de esto, si surgía una controversia entre las partes sobre la presencia de la causal de nulidad, será necesario acudir al juez. León Barandiarán entendió que esta necesidad práctica, eventual en el plano de los hechos, no puede influir en la manera de entender la eficacia del negocio nulo, que se desenvuelve en otro plano, en el de la realidad jurídica. Por lo tanto, si una parte decide no cumplir con lo previsto en un negocio aduciendo la nulidad del mismo, pues estará obrando bajo su propio riesgo. Si el juez o árbitro constata que el negocio efectivamente resulta nulo, pues ninguna responsabilidad soportará. En cambio, si el juez o árbitro dictamina la validez y eficacia, la parte que aducía la nulidad tendrá que soportar las consecuencias nocivas de la negativa a cumplir.

Como hubiera pensado León Barandiarán, siempre es posible que surjan nuevas ideas en el seno de un tema polémico, por más que uno esté convencido de las ideas propias. En ese sentido, con este lo escrito en este capítulo sólo espero haber logrado el objetivo que me tracé al inicio, y así estar más cerca de seguir, de un modo auténtico, las enseñanzas dejadas por la obra y vida del maestro. 
